\title{
Screening for Squints and Amblyopia in Pre-school Children in a Service Community
}

\author{
Lt Col M R Pampapathi \\ FRCS, FRCS(Ophth), RAMC \\ Queen Elizabeth Military Hospital, Woolwich
}

\section{Miss A Cadman}

British Military Hospital, Munster

\begin{abstract}
SUMMARY: A screening programme designed to detect visual defects in pre-school children was mounted in a Service community in West Germany. This showed the feasibility of screening and demonstrated that the results produced were superior to those of routine referral. The methods and findings are discussed.
\end{abstract}

\section{Introduction}

Several studies of screening for visual defects in preschool children have been published in the past 30 years $(1,2,3)$. These have been undertaken because of the importance of identifying children with strabismus and amblyopia of various kinds. Most of them have been done at the age of 3-4 years as it has been found that it is convenient, reliable, and that satisfactory results have been obtained.

No previous screening programmes for the detection of visual defects have been performed in British service communities. Overseas, these communities are served by military hospitals. The people concerned seldom remain in one station for more than two or three years at a time and when posted to the United Kingdom are usually dealt with by the Nathonal Health Service. The effect of this mobility may often be that service children slip through the referral net and fail to benefit from normal management.

In view of this possibility, it was decided to start a programme involving military families served by the British Military Hospital in Münster, West Germany. The main aim was to compare, by age group, the patterns of referral through normal channels with the findings on mass screening.

\section{Materials and Methods}

The British Military Hospital (BMH) Münster, serves a community of 40,000 . This includes 12,000 children under 16 years and about 3,500 below 5 years. 1,200 are aged between 3 and 31/2 years. The staff of the Eye Department at the BMH Münster consists of one ophthalmologist, one orthoptist and one ophthalmic optician.

After reviewing the literature and considering the relative merits of three arbitrary age-groups (under 1

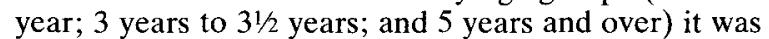
decided, for the following reasons, to opt for the 3 to $3 \frac{1}{2}$ year group:-

Refraction below 1 year is difficult and results unreliable. This is relevent in view of the unique importance of retinoscopy in establishing the refractive status in young children. Spectacle compliance at this age is also poor. School health screening already exists for children over the age of 5 , and this is undesirably late for effective treatment of amblyopia.

In the age-range chosen, diagnosis is reliable, compliance with treatment is likely to be maximal and with proper management gratifying results are possible.

The study was conducted between 1 December 1985 and 30 December 1986. The widest possible publicity was given to the programme. Local service newspapers and specially printed leaflets were used to promote the scheme, and excellent co-operation was obtained frome general practitioners and social workers, who participated actively in the programme.

The orthoptist visited all medical units in the Münste catchment area in turn and all children found to have, of suspected of any visual defects were referred at once to the BMH. The criterion for referral was an acuity in either or both eye of $6 / 9$ or worse.

All children were seen in the presence of at least one parent. A brief general, family and development history was obtained. Visual acuity was tested with the Kay picture test in the first instance in all cases. A quantitative acuity was obtained by this method in 90 per cent. Failing this, the Sheridan Gardiner test was used and we were able to get an assessment of visual acuity on all except five children, and these were automatically referred.

The cover test was done on near fixation both to a light and an accommodative target and then on distance fixation. Positive and negative convergence were checked with an accommodative target. Significantly reduced convergence or distance exotropia were indications for referral. Children who failed to overcome a 20 dioptre base-out prism and those who failed the 4 dioptre prism test were referred. The Lang stereotest was used as it had been found to be more popular and successful with the children than the Wirt Fly or Frisby stereotests. This whole routine was easily accomplished in 10 minutes.

None of the results were made known to the ophthal- 
mologist (M.R.P.) prior to his examination of the referred children. In this all tests were repeated and refraction by retinoscopy was performed 30 minutes after instilling 1 per cent mydrilate drops.

Instead of using a control group it was decided to compare our findings with the figures for a 12 month period obtained from the hospital records of patients referred to the hospital through normal channels before the start of the screening programme. The details are provided in Table 1.

\section{Results}

925 children were examined and 95 cases referred. None of these had previously been suspected of having any ocular pathology (Table 2).

All children with refractive errors were appropriately corrected and assessed 5 weeks later for residual amblyopia. The breakdown of the final findings are given in Tables 2 and 3 .

Approximately $10 \%$ of the children screened were brought to the hospital for reassessment and further investigations. Of 925 children $4.5 \%$ had proven amblyopia. They represented $44.2 \%$ of the children assessed in the hospital.

\section{Discussion}

It is generally agreed that the best prognosis in amblyopia is obtained by detection and management at the earliest possible age. Attempts have been made to identify children at risk as early as one year, and even earlier(4). We did consider the work of Atkinson et al who introduced photoretractive screening for 6-9 month old infants(5). This is clearly a viable option, but since those of our own infants with manifest squints or a strong family history do get referred promptly through normal channels, we felt this group was covered.

It was our view that the group liable to be missed are those aged between 2 years and school age who may develop squints or have anisometropia. Our screening was targetted at this section of the child population. We also believe that retinoscopy and fundal examination are the most objective methods of assessment $(6,7)$. The compliance with spectacle wearing and the cooperation in treatment are at their best on the age group of 3-4 years.

This study was based on the assumption that a compromise between optimum age from a physiological point of view and the optimum for compliance was necessary. There is also proof that better compliance gives improved results even at the age of 6 years and older $(8,9)$. The methods adopted in this study were simple and readily accepted by children and parents. Using an orthoptist for the preliminary screening ensured that only children at risk are seen by the ophthalmologist.

Instead of a control group the figures for referral during the period of the calendar year from July 1984 were used. There was a high false referral rate (37/95).
This may have been due to our anxiety at the inception of the programme. Analysis of early returns for the following year showed that the referral rate was coming down. The referral rate through normal channels shows that the number referred was larger than those referred after screening and nearly half the children referred were picked up after school health examination, while only 16 from the 3-4 year group were referred. The number of amblyopic children was $1 \frac{1 / 2}{2}$ times as high for children over 5 as for those of pre-school age. Our study indicated that, given a screening procedure virtually all those children would have been referred at $31 / 2$ years.

\section{Table 1}

Details of Referrals for the 12 Month Period July 1984 to July 1985 Prior to the Start of the Screening Programme.

\begin{tabular}{|c|c|c|c|c|}
\hline \multirow{2}{*}{$\frac{\text { Age }}{\text { Below } 1 \text { year }}$} & \multicolumn{2}{|c|}{ Referred Findings } & \multicolumn{2}{|c|}{ NAD } \\
\hline & 14 & Congential Squint & 4 & 10 \\
\hline $1-2$ years & 14 & Strabismus & 4 & 10 \\
\hline $2-3$ years & 4 & Strabismic Amblyopia & 2 & 2 \\
\hline $3-4$ years & 16 & $\begin{array}{l}\text { Strabismic Amblyopia } \\
\text { Anisometropic Amblyopia } \\
\text { Refractive Errors Only }\end{array}$ & $\begin{array}{l}2 \\
3 \\
2\end{array}$ & $9 \frac{7}{3}$ \\
\hline $4-5$ years & 10 & $\begin{array}{l}\text { Strabismic Amblyopia } \\
\text { Anisometropic Amblyopia } \\
\text { Refractive Errors Only }\end{array}$ & $\begin{array}{l}1 \\
2 \\
2\end{array}$ & $5 \stackrel{\text { 유 }}{\stackrel{\mathrm{D}}{\stackrel{\mathbb{D}}{\mathbb{Q}}}}$ \\
\hline Over 5 years & $\overline{110}$ & $\begin{array}{l}\text { Strabismic Amblyopia } \\
\text { Anisometropic \& } \\
\text { Strabismic Amblyopia } \\
\text { Refractive Errors Only }\end{array}$ & $\begin{array}{r}5 \\
12 \\
10\end{array}$ & 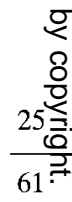 \\
\hline \multicolumn{5}{|c|}{ Children with Amblyopia: } \\
\hline Over 5 yea & & 15 & & \\
\hline
\end{tabular}

Table 2

Results of the Screening Programme $(\mathbf{n}=$ 925)

\begin{tabular}{lll}
\hline Referred to Hospital & & $95(10.3 \%)$ \\
No Abnormality & & $37(4 \%)$ \\
Amblyopia & & $42(4.5 \%)$ \\
$\quad$ Strabismic & 16 & \\
$\quad$ Anisometropic & 16 & \\
Both & 10 & \\
& & \\
Refractive Errors Only & & $16(1.7 \%)$ \\
$\quad$ Myopia & 9 & \\
$\quad$ Astigmatism & 4 & \\
$\quad$ Hypermetropia & 3 & \\
\hline
\end{tabular}


The treatment for amblyopia was along conventional lines - full spectacle correction, occlusion and surgery is indicated. They were all closely monitored by regular orthoptic follow-up. Achievement of $6 / 6$ or at least two Snellen's lines of improvement, and maintenance of these levels of acuity was taken as success. Only 6 cases out of 42 failed to show any improvement and only one child was lost to follow-up. All the amblyopic children under treatment were reviewed at least four times by the authors and were followed up for periods of from 6-18 months.

\section{Conclusions}

By using simple, objective screening methods, applied to children aged 3 to 3 years 6 months, the great majority of those at risk can be identified and effectively treated. Such programmes are particularly relevant in a Service context where the children are constantly moving and are liable to be missed and they may be even more successful in the more stable environment of a civilian community.

\section{REFERENCES}

1. Amigos. Pre-School Vision Study. Br J Ophthalmol 1973; 57: $25-32$.

2. Oliver M, NAWJaTZKI I. Screening of pre-School Children for Ocular Anomalies-I. Br J Ophthamol 1971; 55: 462-6.

3. Oliver M, NAWJATZKI I. Screening of pre-School Children for Ocular Anomalies-II. Br J Ophthamol 1971; 55: 467-72.

4. Ingram R M, Walker C, Wilson J M, ARnold P E, LuCAS J, Dally S. A First Attempt to Prevent Amblyopia and Squints by Spectacle Correction of Abnormal Refractions from Age One Year. Br J Ophthamol 1985; 69: 851-853.

5. Atkinson J, Braddick C J, Durden K, Watson P S, है WATKINSON S. Screening for Refractive Errors in 6-9 Month Old Infants by Photorefraction. Br J Ophthamol 1984; 68: 105-112.

6. INGRAM R M. Refraction as the Basis for Screening Children for Squint and Amblyopia. BrJ Ophthamol 1977; 61: 8-15.

7. InGRam R M. The Problem of Screening Children for Visual Defects. Br J Ophthamol 1977; 61: 4-7.

8. Von Nourden J K, Fadia ATtiah A L. Alternating Penalization in the Prevention of Amblyopia Recurrence. Am J Ophthamol 1986; 102: 473-475.

9. Oliver M, Neumann R, Chaimovitch Y, Gotesman N, SHIMSHON M. Compliance and Results of Treatment for Amblyopia in Children More Than 8 Years Old. Am Ophthamol 1986; 102: 340-345.

\section{HONORARY CONSULTANTS TO THE ARMY}

Mr Barry Jackson has been appointed Honorary Consultant in Surgery to the Army with effect from 30 June 1990. 